\title{
Month Day Imputed
}

National Cancer Institute

\section{Source}

National Cancer Institute. Month Day Imputed. NCI Thesaurus. Code C81211.

An imputed date that includes the month and day of observation. 